\title{
MUDANÇAS CLIMÁTICAS \\ COMPARAÇÃO DA VARIAÇÃO DE TEMPERATURA INTERNA DE UM AMBIENTE REVESTIDO COM TELHADO VERDE E UM COM TELHADO CONVENCIONAL
}

\author{
Thomas Jeferson Vieira (AUTOR PRINCIPAL) - thomas.vieira@ufpr.br \\ Universidade Federal do Paraná. \\ Luciano Fleischfresser (COAUTOR) - lfle @ utfpr.edu.br \\ Universidade Tecnológica Federal do Paraná \\ Lucas Augusto Prudente (COAUTOR) - pruferre@gmail.com \\ Universidade Tecnológica Federal do Paraná.
}

Resumo: A diminuição de áreas verdes em ambientes urbanos pode afetar negativamente o conforto térmico em microescala, sendo necessário um gasto futuro a fim de proporcionar uma temperatura agradável dentro de residências. Este trabalho teve como objetivo apresentar uma comparação da variação das temperaturas internas de um ambiente com telhado coberto por grama formando uma cobertura verde extensiva em relação a um telhado convencional de fibrocimento. Para a realização do experimento foram construídos dois cômodos nas mesmas dimensões com madeira de compensado naval, diferindo apenas na composição do telhado. Os módulos de telhado verde consistiram em uma caixa de madeira, sobreposta por uma camada de impermeabilização, uma camada de filtragem, substrato e placas de grama Zoysia japônica da família Poaceae. Ambos os cômodos estiveram expostos as mesmas condições durante todo o experimento, a fim de se verificar o comportamento das temperaturas internas medidas com termômetros digitais. Durante o período em que o experimento se sucedeu, de 16 de Abril a 17 de Julho, observou-se que o cômodo com telhado verde apresentou uma amplitude menor de variação de temperatura em relação ao cômodo com fibrocimento. Isto é, durante os momentos de maior aquecimento o telhado verde apresentou uma temperatura mais baixa, e nos períodos de pouca ou nenhuma radiação solar, o telhado verde em sua maioria das vezes não chegou a esfriar tanto como o de fibrocimento. Notou-se também que o telhado convencional tendeu a esfriar mais rápido com o chegar da noite.

Palavras-chave: Telhado verde, Temperatura, Sustentabilidade. 

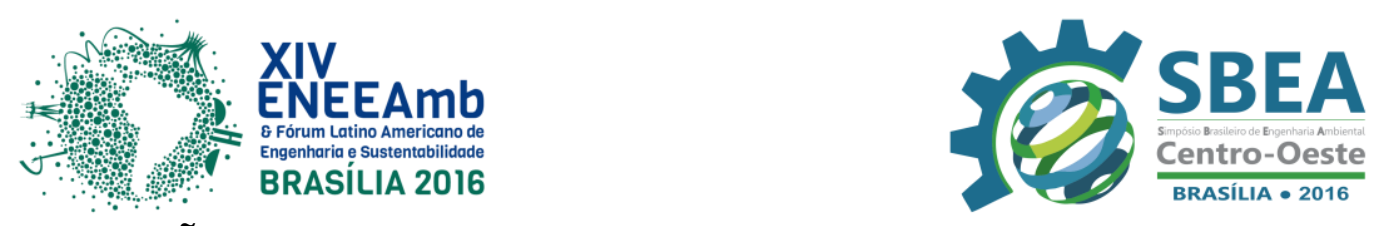

\section{INTRODUÇÃO E OBJETIVOS}

Uma urbanização mal planejada pode causar impactos de grande magnitude, gravidade e intensidade. Considerando esta problemática, se faz necessário o desenvolvimento de técnicas e tecnologias que venham minimizar esses impactos, visando um equilíbrio entre a realização de atividades socioeconômicas e a preservação da qualidade do meio ambiente.

De acordo com Morais (2004) alguns fatores como o adensamento populacional, intensa ocupação territorial, concentração de edificações e também a pavimentação e o acúmulo de poluentes nos grandes centros urbanos, tem contribuído de forma significativa na redução de espaços verdes entre áreas construídas, gerando diversos impactos ambientais adversos. Além disto, a diminuição dessas áreas verdes pode gerar alterações significativas no comportamento térmico em microescala.

O telhado verde é uma técnica construtiva antiga e que é utilizada até hoje. De acordo com Velazquez (2005), a combinação entre plantas e arquitetura não é algo novo pois há registros de construções com plantas desde 2100 A.C. pelos Zigurates da antiga Mesopotâmia, de cabanas da era dos Vikings na Escócia e Irlanda, e também os Jardins Suspensos da Babilônia, representando a mais antiga interpretação de telhado verde, tendo sido construídos entre os séculos 8 e 10 A.C.

A implantação de coberturas verdes tem sido uma alternativa utilizada contra a grande redução de áreas verdes em meio ambientes urbanos. Sailor (2012) ressalta a capacidade do telhado verde em melhoria da qualidade do ar urbano, redução da transmissão de ruído para edifícios, redução da magnitude de ilha de calor urbana e consumo de energia. $\mathrm{O}$ desconforto térmico muitas vezes implica em um maior consumo de energia elétrica por parte dos moradores em regiões afetadas.

Este trabalho teve como objetivo avaliar a variação das temperaturas internas de um ambiente com telhado coberto por gramíneas formando uma cobertura verde extensiva em relação a um telhado convencional de fibrocimento.

\section{METODOLOGIA}

\subsection{Construção dos cômodos de madeira para o experimento}

Foram utilizadas vigas de madeira pinus $5 \mathrm{~cm} \times 10 \mathrm{~cm}$ para a construção das estruturas das duas caixas. Em seguida, placas de compensado naval foram fixadas com prego nas laterais e na parte inferior (chão) das caixas. Por fim, uma porta foi confeccionada para permitir acesso ao interior dos cômodos construídos. Dessa forma, ambos os cômodos possuíam as medidas de $170 \mathrm{~cm}$ de comprimento, por $170 \mathrm{~cm}$ de largura, altura frontal de 170 $\mathrm{cm}$, e ao fundo altura de $210 \mathrm{~cm}$.

Para fixação dos termômetros no interior dos ambientes, foi elaborado um suporte que permitiu que os termopares alcançassem o teto e o centro geométrico de cada caixa. Esses cômodos foram revestidos com telha de fibrocimento fixadas com pregos. Os módulos de telhado verde foram construídos com as dimensões de $244 \mathrm{~cm}$ de comprimento, $56 \mathrm{~cm}$ de largura e $10 \mathrm{~cm}$ de altura. Os três módulos para o telhado verde foram impermeabilizados com uma manta asfáltica, em seguida foram perfurados dois furos, e introduzidos um pequeno cano com raio de $2 \mathrm{~cm}$ em cada furo, para evitar com que água ficasse acumulada ao fundo dos módulos, por se tratar de um telhado inclinado. 

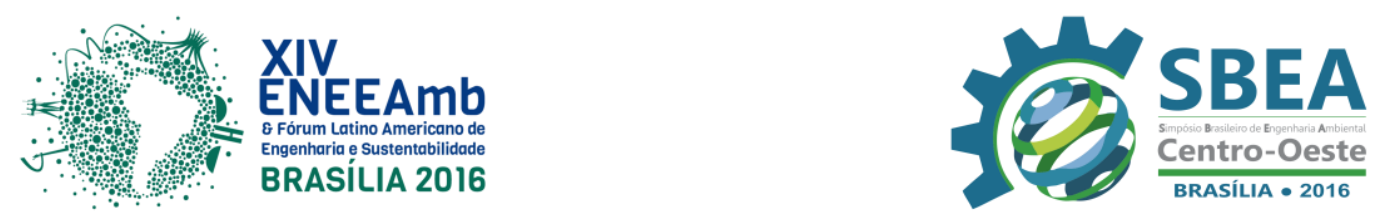

\subsection{Montagem para o experimento}

O experimento foi instalado no Câmpus Campo Mourão da Universidade Tecnológica Federal do Paraná (UTFPR). Foram adquiridas placas de grama Esmeralda, nome Científico: Zoysia japônica da família Poaceae, as quais foram implantadas sobre uma camada de terra de aproximadamente $6 \mathrm{~cm}$ para que a raiz da planta possa obter nutrientes e manter sua sobrevivência quando colocada sobre as caixas para o suporte do telhado verde. Colocou-se também uma camada de argila expandida de aproximadamente $3 \mathrm{~cm}$ abaixo da terra. Lembrando que um dos cômodos teve sobre seu telhado os módulos de telhado verde, enquanto a outra apenas as telhas de fibrocimento. A grama foi regada uma vez por semana a fim de auxiliar no período de adaptação ao telhado.

\subsection{Obtenção e análise dos dados}

Para a obtenção dos dados foram utilizados 2 termômetros digitais do tipo MT - 600, com capacidade para armazenar 10.000 dados. Cada um possuindo 2 termopares, um deles posicionado para medir as variações de temperatura na telha de fibrocimento sendo fixado no lado interno da mesma, e o outro suspenso no centro geométrico da caixa com a finalidade de medir as variações de temperatura do ar interno. Os dados obtidos foram descarregados através de um software próprio dos termômetros. Dados de temperatura externa e radiação solar foram fornecidos pela Estação Meteorológica da própria UTFPR. Os dados foram coletados de $30 \mathrm{em} 30$ minutos. Uma pasta térmica foi utilizada para a fixação dos termopares rente a telha, mantendo-os assim fixos.

A obtenção desses dados foi realizada durante os meses Março de 2014 a Julho de 2014. Nesse período, as variáveis medidas foram: radiação solar, umidade relativa do ar e as temperaturas internas (de ambos protótipos). A partir dos dados coletados, gráficos foram gerados através da linguagem de programação e do programa Python 2.7 com a finalidade de demonstrar e comparar a evolução das temperaturas. Analisando então o comportamento da variação de temperatura interna em cada protótipo, uma vez que ambos estavam sujeitos as mesmas condições, a fim de identificar qual a influência do telhado verde na temperatura interna de um protótipo em relação ao outro com telhado convencional.

\section{RESULTADOS E DISCUSSÕES}

\subsection{Comparação das temperaturas internas entre um cômodo revestido com telhado verde e um apenas com fibrocimento}

Foram escolhidos uma semana representativa da estação de outono e outra para representar o inverno na análise dos resultados. A partir dos dados obtidos, foi possível notar que as temperaturas sob as telhas de ambos os protótipos foram as que mais sofreram variações, isso é, oscilaram com uma amplitude maior, principalmente durante o dia em períodos que a radiação solar é mais intensa. A Figura 1 demonstra as variações de temperaturas das telhas dos dois cômodos durante uma semana do outono, entre os dias 8 a 14 de maio de 2014. É possível observar que a telha revestida com a cobertura verde tem menor variação na temperatura. Durante a semana do dia 8 a 14 de maio, a faixa da variação de temperatura da telha revestida com a cobertura verde é entre 13,6 e $32,6{ }^{\circ} \mathrm{C}$, enquanto a temperatura do telhado com fibrocimento varia entre 9,9 e $42{ }^{\circ} \mathrm{C}$. 


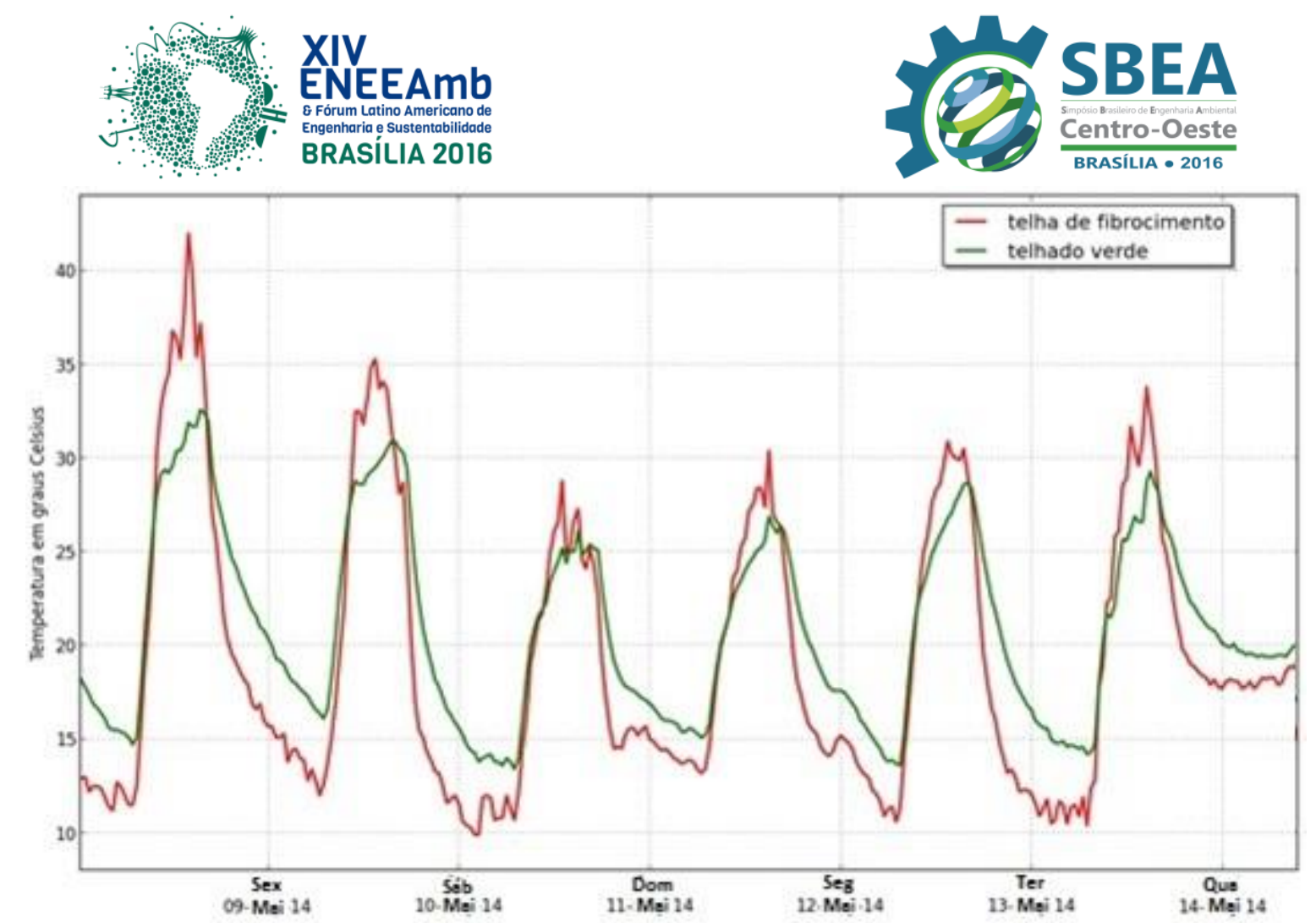

Figura 1: Variação das temperaturas internas das telhas do cômodo com telhado convencional, e o com telhado verde dos dias 8 a 14 de maio de 2014.

Para uma observação do comportamento das temperaturas das telhas durante a estação de inverno, foi escolhido a semana dos dias 10 a 16 de Julho, como exibido na figura 2. É possível observar uma amplitude menor na variação de temperatura, em relação a semana representativa de outono.

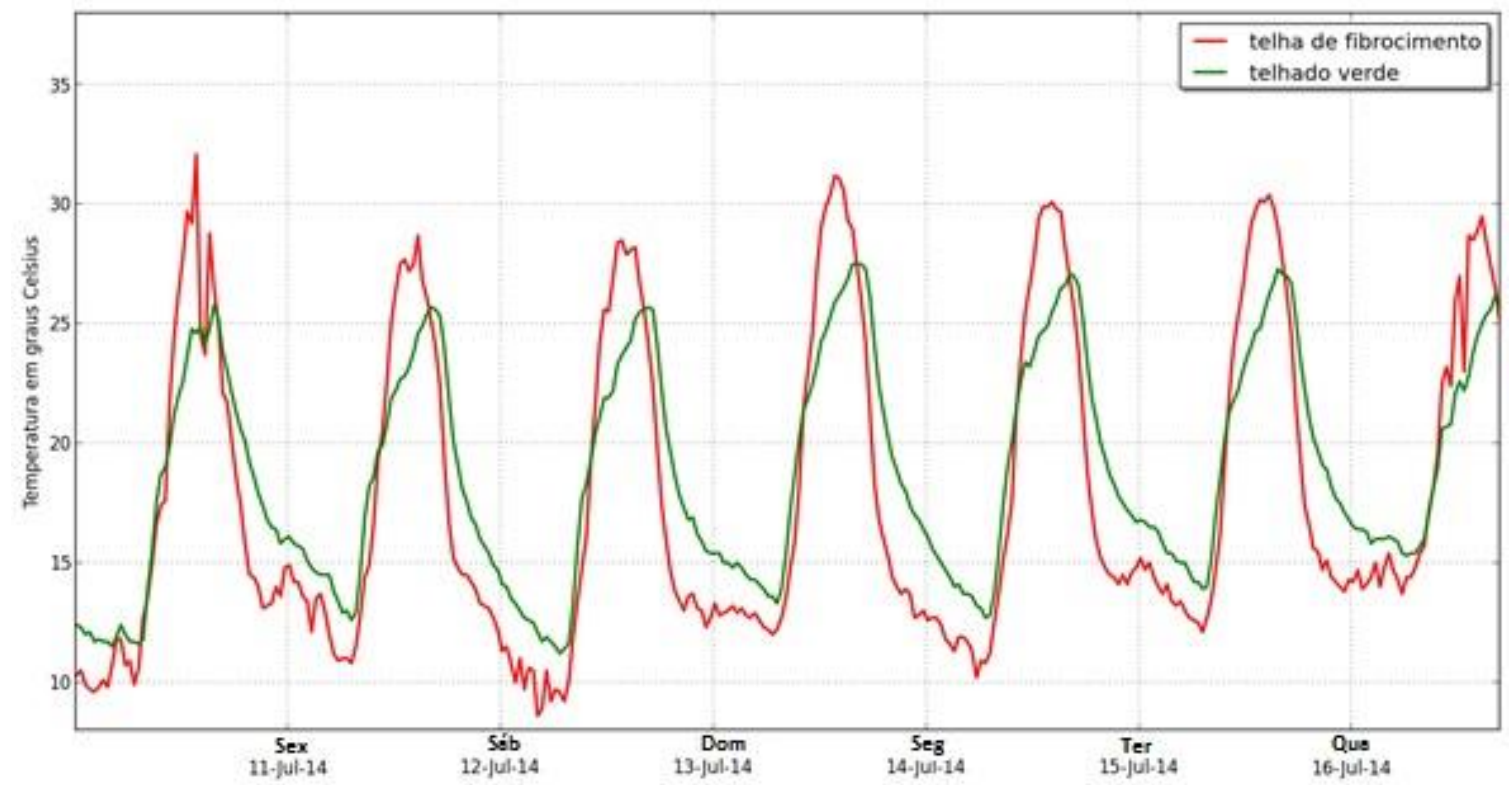

Figura 2- Variação das temperaturas internas das telhas durante a semana dos dias 10 a 16 de Julho.

As temperaturas internas do ar que foram medidas com os termopares que se encontravam suspensos ao centro dos cômodos também mostraram diferenças ao longo do experimento. A figura 3 mostra o a variação das duas temperaturas internas entre os dias 8 a 

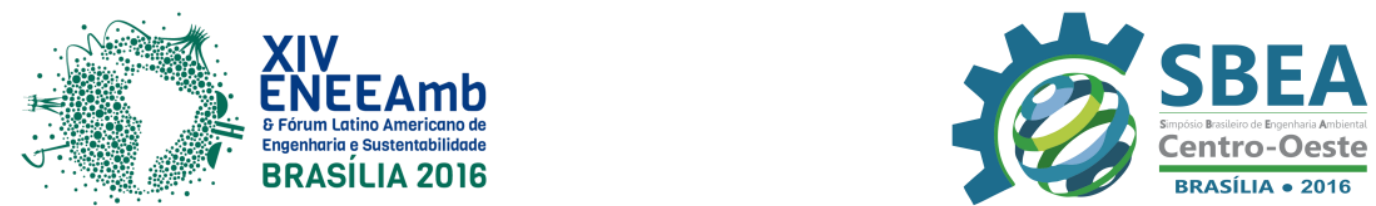

14 de maio. Já a figura 4 exibe a variação das temperaturas durante dos dias 10 a 16 de julho, abrangendo parte da terceira e quarta semana da estação de inverno do hemisfério sul. Através dos gráficos observou-se que a diferença nas variações de temperatura é mais notável nos períodos de radiação solar mais intensa. Nota-se que a taxa de variação entre as temperaturas sob telhas é relativamente maior que a taxa de variação entre as temperaturas do ar interno, devido a sua exposição a variações do tempo externo.

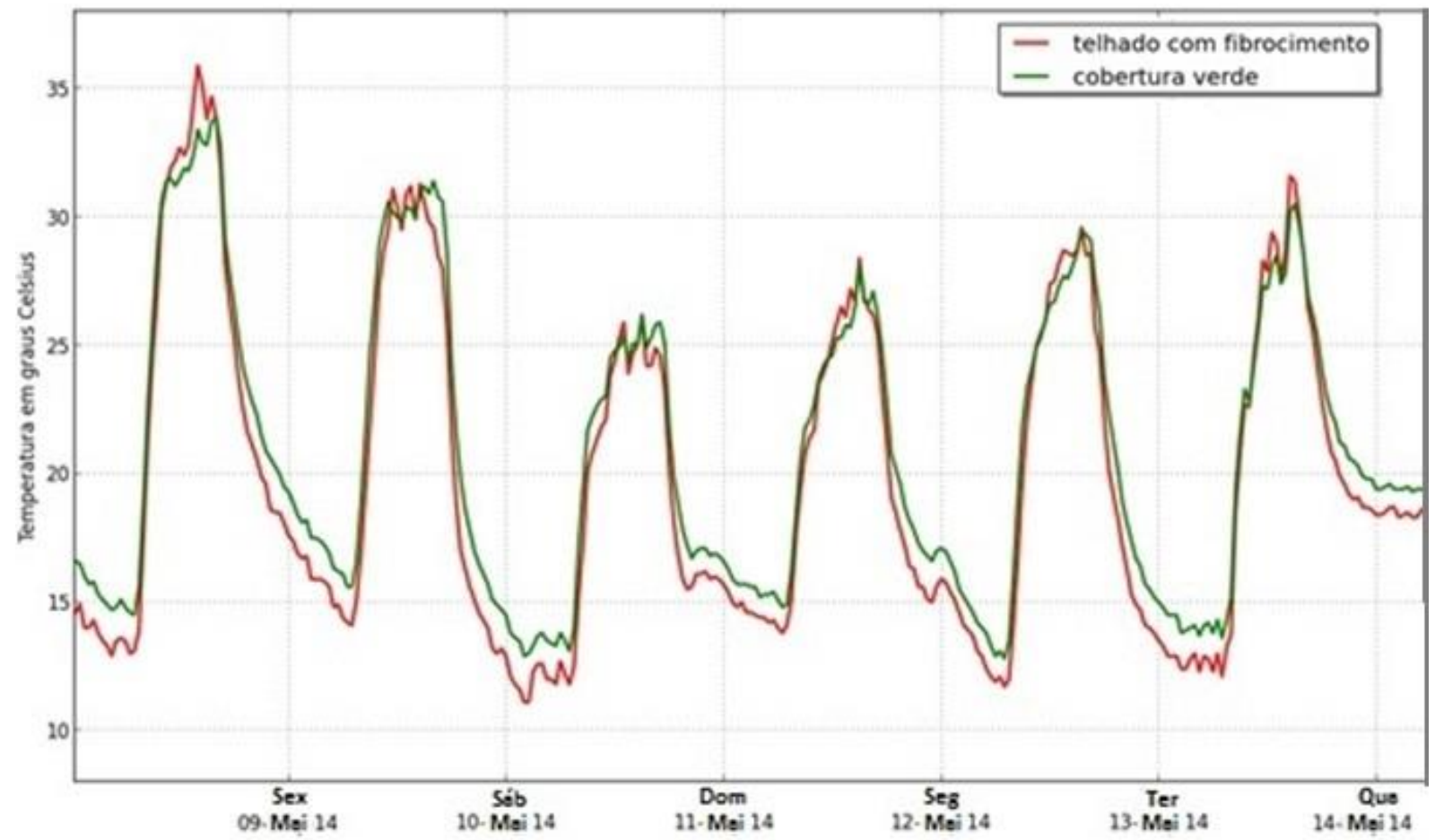

Figura 3 - Gráfico para comparação entre as temperaturas internas dos 2 cômodos entre os dias 8 e 14 de maio de 2014.

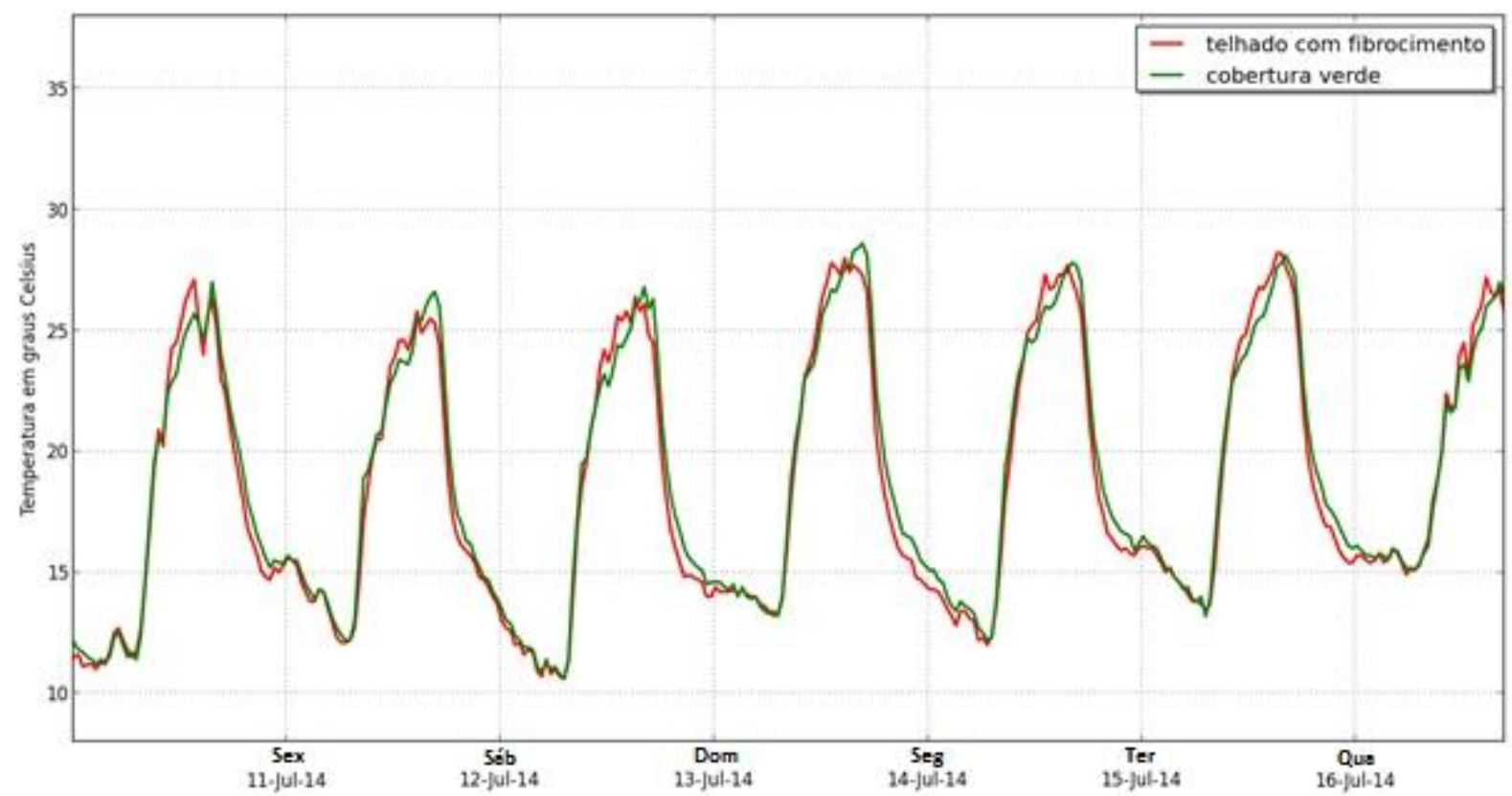

Figura 4 - Temperaturas internas medidas entre os dias 10 a 16 de julho de 2014. 

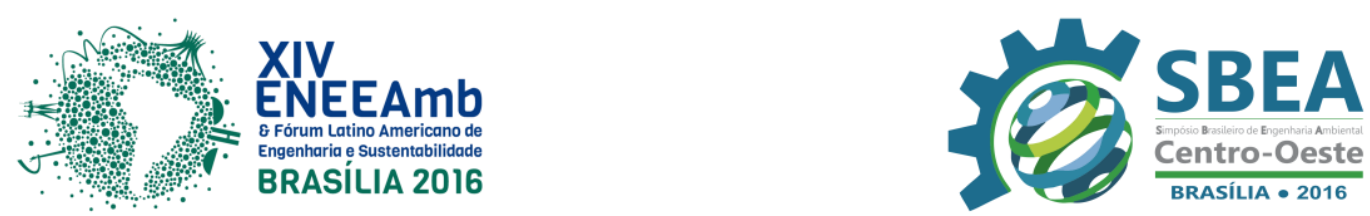

Vale ressaltar novamente que as paredes usadas para o experimento, são de pequena espessura se comparadas a uma casa convencional. Rigão (2012) afirma que a inércia térmica é caracterizada pela capacidade de um material em armazenar e dissipar calor, e a velocidade com que uma parede aquece ou resfria é descrita como inércia térmica. A espessura de uma parede é um dos principais fatores que influenciam na inércia térmica da mesma.

Analisando as figuras 3 e 4 nota-se que as amplitudes de variação térmica são praticamente as mesmas para ambos os telhados. Já no outono, o telhado verde ainda atua para não deixar a temperatura cair muito durante a noite, porém não ajuda muito em reduzir os máximos durante o dia. Entretanto não foram feitas relações entre os dados obtidos e a umidade relativa e resistência térmica do telhado verde, o que limita a análise do porquê do comportamento semelhante.

\subsection{Diferenças de temperaturas internas e radiação solar}

Através dos dados obtidos da Estação Meteorológica Automática presente no próprio Campus, posicionada a poucos metros de onde os cômodos para esse experimento foram posicionados, foi possível gerar séries temporais comparando a diferença de temperaturas internas de cada um dos protótipos, isso é temperatura sob a telha subtraída pela temperatura do ar interno $\left(\mathrm{T}_{1}-\mathrm{T}_{2}\right)$, versus a radiação solar. Podendo então observar o comportamento dessa diferença ao longo dos dias conforme as variações de radiação solar.

$\mathrm{Na}$ figura 5, nota-se que $\mathrm{T}_{1}-\mathrm{T}_{2}$ (temperatura sob a telha menos a temperatura do ar interno) do protótipo com telhado convencional, tende a acompanhar o fluxo de radiação solar. Obteve-se uma temperatura mais elevada sob a telha do que do ar interno nos períodos de maior radiação solar, consequentemente o fluxo de calor no cômodo nesses períodos era do telhado para o interior do cômodo a fim de que o sistema entrasse em equilíbrio térmico.

Já em relação ao protótipo revestido com a cobertura verde, observa-se um comportamento contrário das diferenças entre $\mathrm{T}_{1}$ e $\mathrm{T}_{2}$ durante o mesmo período. Isto é, durante os períodos de maior radiação no dia a cobertura verde ficou mais fria que o interior do cômodo. Isto indica que o fluxo de calor passou ser do interior do cômodo para o telhado. Dessa forma, os resultados apontam que durante a noite as temperaturas da telha no cômodo com telhado verde, estavam maiores do que no outro cômodo. 


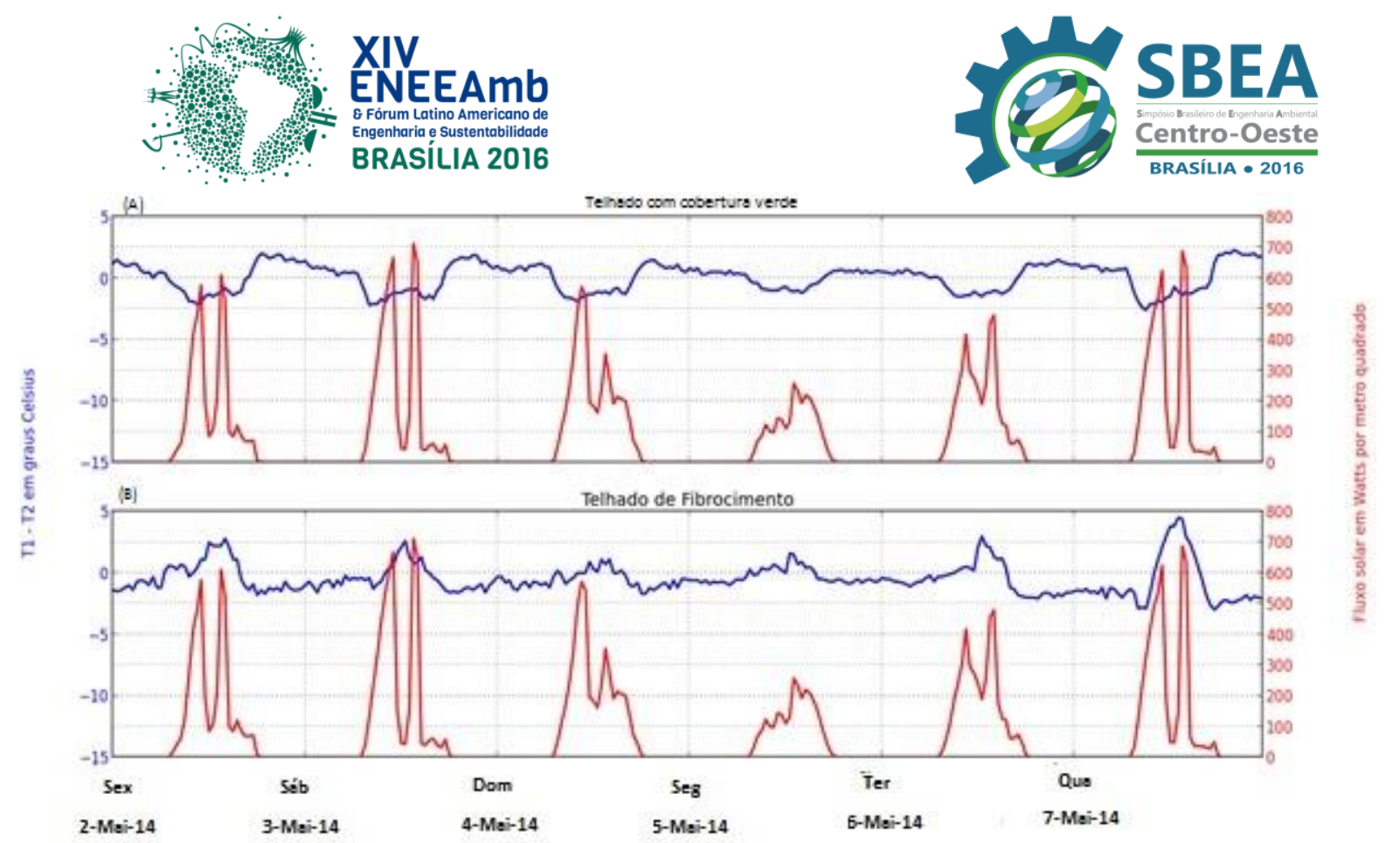

Figura 5: Diferença da temperatura sob a telha do protótipo e a temperatura do ar interno, em relação a variação de radiação solar de 2 a 7 de maio. A) Protótipo com a cobertura verde. B) protótipo sem a cobertura verde.

Nos períodos de radiação solar muito baixa ou nula, observou-se também um comportamento contrário entre as diferenças de $\mathrm{T}_{1}$ e $\mathrm{T}_{2}$ de um protótipo em relação a outro. Durante a noite e madrugada, $\mathrm{O}$ protótipo revestido apenas com telhas de fibrocimento apresentou uma diferença negativa, o que implica em um valor de temperatura interna maior que o da temperatura da telha. Enquanto que a diferença entre $\mathrm{T}_{1}$ e $\mathrm{T}_{2}$ no cômodo revestido com a cobertura verde tendeu a apresentar valores positivos nesses períodos de pouca ou nenhuma radiação solar, o que significa que a temperatura da telha permaneceu na maior parte desse período maior que a temperatura do ar interno.

As caídas abruptas no gráfico da radiação durante os dias 2, 3, 4, 6 e 7 ocorreram devido a um sombreamento do sensor de radiação solar da estação meteorológica.

\section{CONSIDERAÇÕES FINAIS}

Através dos dados obtidos observou-se que o telhado verde tem um papel de atenuar o aumento das temperaturas internas durante o dia, quando comparado com o protótipo só com cobertura de fibrocimento. Essa diferença ficou clara no dia 24 de abril de 2014, quando a temperatura do protótipo com telhado verde chegou a estar $3,7{ }^{\circ} \mathrm{C}$ menor que o ambiente sem telhado verde, o qual se encontrava com uma temperatura interna de $30,3{ }^{\circ} \mathrm{C}$.

Também observou-se que o cômodo revestido com telhado verde demorou mais a esfriar, além de esfriar menos. Na madrugada do dia 10 de maio de 2014, o protótipo revestido com telhado verde chegou a estar com uma temperatura $2,2{ }^{\circ} \mathrm{C}$ maior que do outro protótipo, comprovando assim sua influência na temperatura interna. Notou-se também que nas semanas de inverno, as diferenças na temperatura de um protótipo para o outro foram bem baixas.

\section{Agradecimentos}

Agradecimentos a Universidade Tecnológica Federal do Paraná campus Campo Mourão, a Coordenação do curso de Graduação em Engenharia Ambiental e em especial ao técnico de laboratório Mayko Cristian Sedoski. 


\section{REFERÊNCIAS E CITAÇÕES}

MORAIS, Carolina Santana de. Desempenho Térmico de Coberturas Vegetais em Edificações na Cidade de São Carlos/SP. 108 f. Dissertação (Mestrado). Departamento de Engenharia Civil, Universidade Federal de São Carlos, São Paulo, 2004.

RIGÃO, Alessandro Onofre. Comportamento de Pequenas Parede de Alvenaria Estrutural frente a Altas Temperaturas. Dissertação de Mestrado. Universidade Federal de Santa Maria. Santa Maria- RS, 2012.

SAILOR, David J. ELLEY, Timothy B. GIBSON, Max. Exploring the Building Energy Impacts of Green Roof Design Decisions - A Modeling Study of Buildings in 4 Distinct Climates. Department of Mechanical and Materials Engineering, Portland State University, Portland. Journal of Building Physics. v. 35. 2012.

VACILIKIO, Douglas V. Comparação das Temperaturas Internas de Ambientes com Telhado Verde e Convencional. 2011. 42 f. Monografia. (Curso Superior de Tecnologia em Gestão Ambiental) - Coordenação de Ambiental, Universidade Tecnológica Federal do Paraná. Campo Mourão, 2011.

VECCHIA, Francisco. Cobertura Verde Leve (CVL): Ensaio Experimental. ENCAC ELACAC. Maceió, Alagoas, Brasil. 5 a 7 de Outubro de 2005. p. 2-10.

VELASQUEZ, Linda S. Organic Greenroof Architecture: Sustainable Design for the New Millennium. Wiley Periodicals, Inc Environmental Quality

Management/Summer 2005. p. 2-18 